\title{
Total Body Clearance by Fraction of Dose for Dose Interval Normalized by Weight
}

National Cancer Institute

\section{Source}

National Cancer Institute. Total Body Clearance by Fraction of Dose for Dose Interval

Normalized by Weight. NCI Thesaurus. Code C114229.

The total body clearance for extravascular administration for dose interval based on the fraction of dose absorbed and divided by the weight. 